\title{
Controle da requeima e pinta preta da batata por fungicidas e seu reflexo sobre a produtividade e a qualidade de tubérculos
}

\section{Control of potato late blight and early blight by fungicides and its effects on yield and quality of tubers}

\author{
Jesus Guerino Töfoli1 *, Paulo Cesar Tavares De Melo², Ricardo José Domingues', \\ Josiane Takassaki Ferrari ${ }^{1}$
}

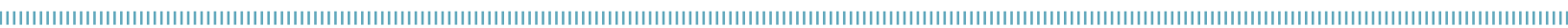

RESUMO: A requeima (Phytophthora infestans) e a pinta preta (Alternaria solani) estão entre as doenças mais frequentes e destrutivas da cultura da batata. Com o objetivo de avaliar a ação de diferentes grupos fungicidas no controle dessas doenças, foram realizados dois experimentos em cultivo comercial de batata (cultivares Agata e Monalisa), localizados em Pilar do Sul, São Paulo, nas safras 2008 e 2009. O delineamento experimental utilizado foi o de blocos ao acaso, com 4 repetiçóes, sendo cada parcela de $20 \mathrm{~m}^{2}$. As aplicaçôes foram realizadas com um pulverizador costal, munido de barra de aplicação e pressão constante de 3 Bar. $\mathrm{O}$ volume de aplicaçáo variou de 300 a 500 L.ha ${ }^{-1}$ em funçáo do desenvolvimento da cultura. As variáveis avaliadas para as duas doenças foram: severidade em folhas, área abaixo da curva de progresso da doença (AACPD), produtividade total e comercial, e classificaçáo de tubérculos. Os menores níveis de doença e aumentos significativos na produtividade comercial e qualidade de tubérculos foram observados nas parcelas tratadas com fluopicolide + propamocarbe, dimetomorfe + ametoctradina, mandipropamida + clorotalonil, mandipropamida, fenamidona + propamocarbe, bentiavalicarbe + fluazinam, seguidos de dimetomorfe + clorotalonil, mefenoxam + clorotalonil e famoxadona + cimoxanil + mancozebe para requeima, e azoxistrobina + difenoconazol, picoxistrobina, piraclostrobina + metconazol, trifloxistrobina + tebuconazol, azoxistrobina, boscalida + piraclostrobina, iprodiona + pirimetanil e ciprodinil para pinta preta.

PALAVRAS-CHAVE: Solanum tuberosum L.; Phytophthora infestans; Alternaria solani; controle químico.
ABSTRACT: Late blight (Phytophthora infestans) and early blight (Alternaria solani) are among the most current and destructive diseases of potato. With the aim of evaluating the efficiency of different fungicides in the control of both diseases, two experiments were carried out in commercial potato crops (cultivars Agata and Monalisa) in Pilar do Sul, Sáo Paulo State, Brazil, during 2008 and 2009 cropping season. Randomized block designs were used, with 4 replications and each parcel of $20 \mathrm{~m}^{2}$. Applications were carried out using coastal sprayer with spray-bar under constant pressure of 3 Bar. The application volume varied from 300 to $500 \mathrm{~L}$ per hectare according to the crop development. The evaluated variables for both diseases were: severity on leaves, area under disease progress curve (AUDPC), total and commercial yield, and classification of tubers. For late blight, the lower severity levels and significant increases in commercial yield and quality tubers were observed on the rows treated with fluopicolide + propamocarb, dimetomorph + ametoctradin, mandipropamid + chlorothalonil, mandipropamid, fenamidone + propamocarb, benthiavalicarb + fluazinam, followed by dimetomorph + chlorothalonil, mefenoxam + chlorothalonil e famoxadone + cymoxanil + mancozeb and, for early blight, azoxystrobin + difenoconazole, picoxystrobin, pyraclostrobin +metconazole, trifloxystrobin + tebuconazole, azoxystrobin, boscalid + pyraclostrobin, iprodione + pyrimethanil and cyprodinil.

KEYWORDS: Solanum tuberosum L.; Phytophthora infestans; Alternaria solani; chemical control. 


\section{INTRODUÇÃO}

A requeima causada pelo Oomycota Phytophthora infestans (Mont.) de Bary e a pinta preta, ocasionada pelo fungo Alternaria solani Sorauer, representam as doenças mais importantes e destrutivas da cultura da batata no Brasil e no mundo (Dias; IAmauti, 2005; Töfoli et al., 2012a).

Favorecida por períodos de alta umidade e temperaturas amenas, a requeima pode ocorrer em qualquer fase da cultura, afetando drasticamente folhas, hastes, pecíolos e tubérculos. A doença reduz de forma significativa a produtividade e a qualidade, podendo causar elevadas perdas em curto espaço de tempo (Mizubuti, 2001; Stevenson; et al., 2008).

A pinta preta é caracterizada pela redução da área foliar, queda de vigor, quebra de hastes e redução da produçáo. Comum em períodos quentes e úmidos, a doença geralmente está associada ao amadurecimento dos tecidos e torna-se mais agressiva a partir das fases de formação e crescimento dos tubérculos (TÖFOLI et al., 2015; WALE et al., 2008).

Programas de produçáo integrada têm recomendado, para o manejo da requeima e pinta preta da batata, a adoção de medidas conjuntas de controle como: uso de sementes certificadas; plantio de cultivares com algum nível de resistência; evitar o plantio em áreas úmidas e sujeitas à neblina; evitar irrigaçóes excessivas; adubação equilibrada; rotação de culturas; eliminação de restos culturais; controle de plantas daninhas e aplicação de fungicidas (Stevenson et al., 2008; Töfoli et al., 2013a).

A maioria das cultivares com expressão comercial no Brasil se mostra suscetível ou moderadamente suscetível à requeima eà pinta preta, o que torna necessária a utilizaçâo de fungicidas para a obtenção de níveis competitivos de produtividade. Esses são aplicados inicialmente para prevenir e depois para retardar a evolução dessas doenças durante o ciclo da cultura. $\mathrm{O}$ êxito no uso desses produtos geralmente está condicionado a vários fatores, como: suscetibilidade da cultivar, pressáo de doença, clima, escolha do fungicida adequado, tecnologia de aplicação, momento oportuno para o tratamento, bem como o número e o intervalo entre aplicaçóes (Töfoli et al., 2013b).

Nos últimos anos, novos produtos têm sido desenvolvidos no Brasil para o controle da requeima e pinta preta da batata. Entre os mais recentes para requeima destacam-se os produtos à base de mandipropamida (Huggenberger; KNAuf-Beiter, 2007), fluopicolide (Tafforeau et al., 2006), bentiavalicarbe (Mirake et al., 2005) e ciazofamida (Ebersold, 2002). Para a pinta preta tem-se observado principalmente o lançamento de misturas entre estrobilurinas (azoxistrobina, trifloxistrobina; SAUTER, 2007) com triazóis (difenoconazol, tebuconazol; KuCK; Vors, 2007) e carboximidas (boscalida; RHEINHEIMER, 2007). Entre as moléculas mais atuais para o controle da requeima e da pinta preta encontram-se a ametoctradina (Gold et al., 2009) e a picoxistrobina (SAUTER, 2007), respectivamente.

Considerando a importância do uso de fungicidas para a sustentabilidade da cadeia produtiva da batata e a introduçấo de novas moléculas nos últimos anos, o presente trabalho objetivou avaliar o controle da requeima e da pinta preta da batata por esses produtos e seus reflexos sobre a produção e a qualidade de tubérculos.

\section{MATERIAL E MÉTODOS}

Os experimentos 1 e 2 foram conduzidos em plantios comerciais de batata, localizados no município de Pilar do Sul, São Paulo, safras 2008 e 2009.

No experimento 1, realizado no período de abril a junho de 2008, os fungicidas (\% de ingrediente ativo; $\mathrm{kg}$ ou $\mathrm{L}$ de produto formulado por hectare) testados para requeima foram: piraclostrobina + metiram $(5+50 \% ; 1,5)$, dimetomorfe + clorotalonil $(50 \% / 82,5 \% ; 0,45+1,5)$, dimetomorfe + mancozebe $(50 \%$ e $80 \% ; 0,45+3,0)$, dimetomorfe + ametoctradina $(22,5+30 \%$; $1,0)$, mandipropamida $(25 \% ; 0,4)$, mandipropamida + clorotalonil $(4+40 \% ; 2,0)$, mefenoxam + mancozebe $(6,25+62,5 \%$; $2,5)$, mefenoxam + clorotalonil $(6,75+67,5 \% ; 1,5)$, cimoxanil + mancozebe $(8+64 \% ; 2,0)$, cimoxanil + zoxamida $(33,1+33,1 \%$; $0,4)$, bentiavalicarbe + fluazinam $(10+25 \% ; 0,7)$, famoxadona + cimoxanil $(22,5+33 \%$; 0,6), famoxadona + mancozebe $(6,25+62,5 \% ; 1,6)$, famoxadona + cimoxanil + mancozebe $(22,5+33 \% / 80 \% ; 0,6+3,0)$, fenamidona $(50 \%$; 0,3$)$, fenamidona + propamocarbe $(7,5+37,5 \% ; 1,7)$, fluopicolide + propamocarbe $(6,25+62,5 \% ; 1,5)$, propamocarbe $(72,2 \%$; $1,25)$, ametoctradina + metiram $(1,2+44 \% ; 2,0)$ ciazofamida $(40 \% ; 0,25)$ e fluazinam $(50 \% ; 1,0)$.

No experimento 2, realizado no período outubro a dezembro de 2009, os fungicidas testados para pinta preta (\% de ingrediente ativo; $\mathrm{kg}$ ou $\mathrm{L}$ de produto formulado por hectare) foram: picoxistrobina $(25 \% ; 0,25)$, azoxistrobina $(50 \% ; 0,08)$, azoxistrobina + difenoconazol $(20+12,5 \% ; 0,75)$, piraclostrobina + metiram $(5+50 \% ; 1,5)$, piraclostrobina + metconazol $(13+18 \% ; 0,6)$, trifloxistrobina + tebuconazol $(20+10 \%$; $0,75)$, tebuconazol $(20 \% ; 1,0)$, difenoconazol $(25 \% ; 0,3)$, flutriafol $(12,5 \% ; 0,75)$, metconazol $(9 \% ; 1,0)$, boscalida $(50 \% ; 0,10)$, boscalida + piraclostrobina $(20+10 \% ; 0,25)$, famoxadona + mancozebe $(6,25+62,5 \% ; 1,6)$, iprodiona $(50 \% ; 1,0)$, pirimetanil $(30 \% ; 1,0)$, iprodiona + pirimetanil $(50 \% / 30 \% ; 0,3+0,5)$, ciprodinil $(75 \% ; 0,25)$, fluazinam $(50 \% ; 1,0)$, clorotalonil $(82,5 \% ; 1,5)$.

Nos experimentos 1 e 2 foram utilizadas as cultivares Agata e Monalisa, respectivamente. As pulverizaçóes foram iniciadas de forma preventiva, aos 25 e 40 dias após a emergência (DAE), respectivamente. Para tanto, foi utilizado um pulverizador costal pressurizado a $\mathrm{CO}_{2}$, munido de barra de aplicação e pressão constante de 3 Bar regulado de forma a proporcionar cobertura adequada do alvo. A barra de aplicação continha cinco bicos cônicos do tipo TXKV26, espaçados de $0,5 \mathrm{~m}$, sendo a distância entre a barra e o alvo durante a aplicação de aproximadamente $0,5 \mathrm{~m}$. $\mathrm{O}$ volume 
de aplicação variou de 300 a 500 L.ha-1 em função do desenvolvimento da cultura. Foram realizadas 6 aplicaçóes a intervalos de 5 a 7 dias no experimento 1 e 5 aplicaçôes a intervalos de 6 a 8 dias no experimento 2. Nos períodos pré e pós-aplicação dos tratamentos foram realizadas 3 aplicaçóes de clorotalonil $(1,5 \mathrm{~kg}$ de produto concentrado por hectare) nos 2 experimentos.

No experimento 1 , as características avaliadas foram: a) Severidade em folhas: a porcentagem $(0$ a $100 \%)$ de área foliar afetada pela requeima foi avaliada com uma adaptação da escala proposta por Cruikshank et al. (1982). Foram realizadas sete avaliaçóes a intervalos de cinco a sete dias, considerando todas as plantas das cinco linhas centrais de cada parcela. b) Área abaixo da curva de progresso da requeima (AACPR). Os valores obtidos ao longo das avaliaçóes de severidade foram utilizados para calcular o progresso da doença conforme proposto por Campbell; Madden, 1990. Os valores da AACPR foram padronizados dividindo-se cada valor pelo número de dias da epidemia. c) Severidade em haste: foi avaliada através de uma escala de notas de 1 a 5 , onde considerou-se a porcentagem da haste coberta por lesôes onde: 1- ausência de sintomas; 2 0,1 a $5 \%$; 3-5, 1 a $10 \%$; 4-10, 1 a 15\%; 5- lesóes acima de $15 \%$ e/ou morte do ponteiro.

No experimento 2, a severidade da pinta preta em folhas foi avaliada por meio de uma adaptação da escala proposta por ReifsChNeIDer et al. (1984), em que foram considerados os níveis de $0 ; 2,5 ; 12 ; 25 ; 50 ; 75$ e 100\% de área foliar afetada pela doença. Foram avaliadas 25 folhas escolhidas ao acaso nos terços inferior e médio de plantas localizadas nas 5 linhas centrais de cada parcela. Foram realizadas sete avaliaçóes a intervalos de sete dias. O cálculo da área abaixo da curva de progresso da pinta preta (AACPPP) foi realizado de forma semelhante ao realizado para requeima.

As variáveis referentes à produção de tubérculos nos experimentos 1 e 2 foram: produtividade total $\left(\mathrm{kg} .10 \mathrm{~m}^{-2}\right)$, produtividade comercial $\left(\mathrm{kg} .10 \mathrm{~m}^{-2}\right)$ e classificaçáo de tubérculos por tamanho (maior diâmetro transversal, em milímetros $\mathrm{mm}$, onde, Classe I: > $70 \mathrm{~mm}$; Classe II: 42 a $70 \mathrm{~mm}$; Classe III: 33 a $42 \mathrm{~mm}$; Classe IV: 28 a $33 \mathrm{~mm}$.

Os dados foram submetidos à análise da variância, aplicando-se o teste Tukey a $5 \%$ de probabilidade para a comparação das médias.

\section{RESULTADOS E DISCUSSÃO}

No experimento 1, a ocorrência de condiçóes climáticas favoráveis aliadas à suscetibilidade da cultivar Agata favoreceu o aparecimento da requeima e o seu rápido desenvolvimento nas parcelas testemunhas.

Os primeiros sintomas da doença e a destruição completa da parte área das plantas nas testemunhas foram observados aos 40 e 65 DAE, respectivamente. Todos os tratamentos testados foram superiores à testemunha. Os menores níveis de severidade (folhas e hastes) e progresso da requeima foram observados nas parcelas tratadas com mandipropamida + clorotalonil, fluopicolide + propamocarbe e dimetomorfe + ametoctradina, sendo esses superiores a fluazinam, ciazofamida, propamocarbe, fenamidona, famoxadona + cimoxanil + mancozebe, famoxadona + cimoxanil, cimoxanil + mancozebe, cimoxanil + zoxamida, mefenoxam + clorotalonil, mefeno$\mathrm{xam}+$ mancozebe, amectotradina + metiram, dimetomorfe + clorotalonil e dimetomorfe + mancozebe e semelhante aos demais tratamentos. Famoxadona + mancozebe e fluazinam foram os tratamentos menos eficientes. Os valores da AACPR variaram de 2,18 a 63,45 (Tabela 1).

A variação na severidade e evolução da requeima proporcionada pelos fungicidas, em relação à testemunha, foi determinante sobre a produtividade total, comercial e classificação de tubérculos (Tabela 2). Fluopicolide + propamocarbe promoveu a maior produtividade total, sendo superior a fluazinam, cimoxanil + mancozebe, mefenoxam + mancozebe, dimetomorfe + mancozebe e semelhante aos demais. Quanto à produtividade comercial, destacaram-se os tratamentos mandipropamida + clorotalonil e fluopicolide + propamocarbe, sendo esses superiores a mefenoxam + mancozebe, famoxadona + mancozebe, cimoxanil + mancozebe e fluazinam, e semelhantes aos restantes.

Quanto à classificaçáo, observou-se que as parcelas pulverizadas com fungicidas apresentaram maiores quantidades de tubérculos das classes I, enquanto que na testemunha prevaleceram as classes II, III e IV. A maior quantidade de tubérculos da classe I foi obtida com fluopicolide + propamocarbe, sendo essa superior às obtidas com dimetomorfe + mancozebe, ametoctradina + metiram, mefenoxam + mancozebe, cimoxanil + mancozebe, cimoxanil + zoxamida, bentiavalicarbe + fluazinam, famoxadona + cimoxanil, famoxadona + mancozebe, famoxadona + cimoxanil + mancozebe, fenamidona, propamocarbe, ciazofamida, fluazinam e semelhante às demais. Famoxadona + cimoxanil + mancozebe promoveu maior quantidade de tubérculos da classe II, sendo superior a dimetomorfe + mancozebe, mefenoxam + mancozebe, cimoxanil + mancozebe, cimoxanil + zoxamida e fenamidona, porém semelhante aos demais. Nas classes III e IV não foram observadas diferenças significativas entre os tratamentos.

No experimento 2, a pinta preta atingiu $85 \%$ da área foliar da testemunha aos $87 \mathrm{DAE}$. Os primeiros sintomas da doença foram observados nas parcelas testemunhas, aos 52 DAE (Tabela 3).

A maior redução da severidade e progresso da pinta preta foi observada nos tratamentos azoxistrobina + difenoconazol sendo esse superior ao famoxadona + mancozebe, boscalida, metconazol, tebuconazol, flutriafol, difenoconazol, tebuconazol, piraclostrobina + metiram, pirimetanil, iprodiona, fluazinam, clorotalonil, e semelhante aos demais 
Tabela 1. Severidade em folhas, haste e área abaixo da curva de progresso da requeima no cultivo de batata (cultivar Agata) tratada com fungicidas. Pilar do Sul, São Paulo, abril a junho 2008.

\begin{tabular}{|c|c|c|c|}
\hline \multirow[b]{2}{*}{ Tratamentos } & \multicolumn{2}{|c|}{ Severidade } & \multirow[b]{2}{*}{ AACPR } \\
\hline & $\begin{array}{c}\text { \% de área foliar afetada } \\
\text { (65 DAE) }\end{array}$ & $\begin{array}{l}\text { Haste } \\
\text { (60 DAE) }\end{array}$ & \\
\hline Testemunha & $100,00^{a *}$ & $5,00^{a * *}$ & $63,45^{a}$ \\
\hline Piraclostrobina + metiram & $25,25^{\text {cdef }}$ & $2,28^{\text {defg }}$ & $8,18^{\text {def }}$ \\
\hline Dimetomorfe + clorotalonil & $18,03^{\mathrm{fg}}$ & $2,10^{\text {defgh }}$ & $6,07^{\text {fgh }}$ \\
\hline Dimetomorfe + mancozebe & $26,75^{\text {cde }}$ & $2,58^{\text {cde }}$ & $10,18^{\text {cde }}$ \\
\hline Dimetomorfe + ametoctradina & $9,25^{h}$ & $1,43^{h}$ & $2,88^{\text {hi }}$ \\
\hline Ametoctradina + metiram & $28,05^{\text {cde }}$ & $2,28^{\text {defg }}$ & $9,35^{\text {cdef }}$ \\
\hline Mandipropamida & $11,25^{\text {gh }}$ & $1,65^{\text {gh }}$ & $2,63^{\mathrm{hi}}$ \\
\hline Mandipropamida + clorotalonil & $7,85^{\mathrm{h}}$ & $1,35^{\mathrm{h}}$ & $2,18^{i}$ \\
\hline Mefenoxam + mancozebe & $28,75^{\mathrm{cd}}$ & $2,20^{\text {efg }}$ & $11,03^{\mathrm{cd}}$ \\
\hline Mefenoxam + clorotalonil & $19,50^{\text {efg }}$ & $1,73^{\text {fgh }}$ & $6,15^{\text {fgh }}$ \\
\hline Cimoxanil + mancozebe & $32,75^{c}$ & $2,73^{\mathrm{cd}}$ & $12,08^{c}$ \\
\hline Cimoxanil + zoxamida & $25,05^{\text {def }}$ & $2,23^{\text {defg }}$ & $9,20^{\text {cdef }}$ \\
\hline Bentiavalicarbe + fluazinam & $12,75^{\mathrm{gh}}$ & $1,62^{\text {gh }}$ & $3,28^{\text {ghi }}$ \\
\hline Famoxadona + cimoxanil & $24,28^{\text {def }}$ & $2,40^{\text {cdef }}$ & $7,96^{\text {def }}$ \\
\hline Famoxadona + mancozebe & $41,25^{b}$ & $3,05^{b c}$ & $16,68^{b}$ \\
\hline Famoxadona + cimoxanil + mancozebe & $20,08^{\text {efg }}$ & $2,13^{\text {defgh }}$ & $6,45^{\text {fgh }}$ \\
\hline Fenamidona & $23,75^{\text {def }}$ & $2,15^{\text {efg }}$ & $7,36^{\text {def }}$ \\
\hline Fenamidona + propamocarbe & $12,50^{\text {gh }}$ & $1,65^{\text {gh }}$ & $3,50^{\text {ghi }}$ \\
\hline Fluopicolide + propamocarbe & $8,50^{h}$ & $1,48^{h}$ & $2,25^{i}$ \\
\hline Propamocarbe & $26,75^{\text {cde }}$ & $2,18^{\text {efg }}$ & $10,00^{\text {cde }}$ \\
\hline Ciazofamida & $27,70^{\text {cd }}$ & $2,33^{\text {defg }}$ & $9,28^{\text {cdef }}$ \\
\hline Fluazinam & $46,50^{b}$ & $3,73^{b}$ & $20,15^{b}$ \\
\hline CV (\%) & 12,86 & 10,72 & 13,26 \\
\hline
\end{tabular}

DAE: dias após a emergência; AACPR: área abaixo da curva de progresso da requeima; médias seguidas de mesma letra não diferem entre si pelo teste de Tukey a $5 \%$ de probabilidade; * médias seguidas de mesma letra não diferem entre si pelo teste de Tukey a $5 \%$ de probabilidade. **Escala de notas de 1 a 5; CV: coeficiente de variação.

Tabela 2. Produtividade total, comercial e classificação de tubérculos comerciais obtidos de plantas de batata (cultivar Agata) tratadas com fungicidas contra a requeima. Pilar do Sul, São Paulo, abril a junho de 2008.

\begin{tabular}{|c|c|c|c|c|c|c|}
\hline \multirow[t]{2}{*}{ Tratamentos } & \multicolumn{3}{|c|}{ Produtividade $\left(10 \mathrm{~m}^{-2}\right)$} & \multicolumn{3}{|c|}{$\begin{array}{l}\text { Classificação de tubérculos } \\
\text { comerciais }\left(10 \mathrm{~m}^{-2}\right)\end{array}$} \\
\hline & Total & Comercial & Classe IV & Classe III & Classe II & Classe I \\
\hline Testemunha & $11,25^{e}$ & $7,53^{f}$ & $1,95^{\mathrm{aB} *}$ & $2,85^{\mathrm{aAB}}$ & $3,13^{\mathrm{dA}}$ & $0,93^{\mathrm{hB}}$ \\
\hline Piraclostrobina + metiram & $27,45^{\text {abcd }}$ & $26,20^{\mathrm{abcd}}$ & $2,38^{\mathrm{aD}}$ & $4,43^{\mathrm{ac}}$ & $6,68^{\mathrm{abcB}}$ & $13,35^{\mathrm{abcdA}}$ \\
\hline Dimetomorfe + clorotalonil & $27,90^{\text {abcd }}$ & $26,68^{\mathrm{abcd}}$ & $1,70^{\mathrm{ac}}$ & $3,50^{\mathrm{ac}}$ & $6,73^{\mathrm{abcB}}$ & $14,45^{\mathrm{abcA}}$ \\
\hline Dimetomorfe + mancozebe & $24,38^{\mathrm{bcd}}$ & $22,85^{\text {bcde }}$ & $1,85^{\mathrm{ac}}$ & $3,93^{\mathrm{aB}}$ & $5,25^{\mathrm{cdB}}$ & $12,18^{\text {cdeA }}$ \\
\hline Dimetomorfe + ametoctradina & $28,75^{\mathrm{abcd}}$ & $28,00^{\mathrm{ab}}$ & $1,35^{\mathrm{aD}}$ & $4,83^{\mathrm{ac}}$ & $7,25^{\mathrm{abcB}}$ & $15,08^{\mathrm{abA}}$ \\
\hline Ametoctradina + metiram & $26,70^{\text {abcd }}$ & $25,05^{\text {abcde }}$ & $2,00^{\mathrm{aD}}$ & $4,28^{\mathrm{ac}}$ & $7,10^{\mathrm{abcB}}$ & $10,45^{\text {efA }}$ \\
\hline Mandipropamida & $28,93^{\mathrm{abc}}$ & $27,63^{\mathrm{abc}}$ & $2,25^{\mathrm{aD}}$ & $4,75^{\mathrm{ac}}$ & $7,55^{\mathrm{abcB}}$ & $12,98^{\text {abcdeA }}$ \\
\hline Mandipropamida + clorotalonil & $29,50^{\mathrm{ab}}$ & $28,88^{a}$ & $1,83^{\mathrm{aD}}$ & $4,50^{\mathrm{ac}}$ & $8,43^{\mathrm{abB}}$ & $14,63^{\mathrm{abcA}}$ \\
\hline Mefenoxam + mancozebe & $24,28^{\mathrm{bcd}}$ & $22,65^{\text {bcde }}$ & $2,15^{a c}$ & $3,50^{\mathrm{aBC}}$ & $5,08^{\mathrm{cdB}}$ & $12,48^{\text {bcdeA }}$ \\
\hline Mefenoxam + clorotalonil & $26,15^{\mathrm{abcd}}$ & $24,83^{\text {abcde }}$ & $2,53^{a c}$ & $3,88^{\mathrm{ac}}$ & $6,13^{\mathrm{abcB}}$ & $12,83^{\text {abcdeA }}$ \\
\hline Cimoxanil + mancozebe & $24,13^{\mathrm{bcd}}$ & $22,00^{\text {cde }}$ & $2,28^{a c}$ & $3,18^{\mathrm{ac}}$ & $5,70^{\mathrm{cdB}}$ & $11,13^{\text {deA }}$ \\
\hline Cimoxanil + zoxamida & $25,08^{\text {abcd }}$ & $24,20^{\text {abcde }}$ & $2,03^{a c}$ & $4,65^{\mathrm{aB}}$ & $6,03^{\mathrm{bcB}}$ & $11,30^{\text {defA }}$ \\
\hline Bentiavalicarbe + fluazinam & $27,30^{\text {abcd }}$ & $25,78^{\text {abcde }}$ & $2,15^{\mathrm{ac}}$ & $5,25^{\mathrm{aB}}$ & $6,58^{\mathrm{abcB}}$ & $12,10^{\text {cdeA }}$ \\
\hline Famoxadona + cimoxanil & $27,08^{\mathrm{abcd}}$ & $25,40^{\text {abcde }}$ & $2,83^{\mathrm{aD}}$ & $4,80^{\mathrm{ac}}$ & $7,15^{\mathrm{abcB}}$ & $10,50^{\text {efA }}$ \\
\hline Famoxadona + mancozebe & $23,53^{\mathrm{cd}}$ & $20,95^{\text {de }}$ & $2,05^{\mathrm{ac}}$ & $3,23^{\mathrm{ac}}$ & $6,50^{\mathrm{abcB}}$ & $9,28^{\mathrm{fgA}}$ \\
\hline Famoxadona + cimoxanil + mancozebe & $29,78^{\mathrm{ab}}$ & $27,40^{\mathrm{abc}}$ & $2,85^{\mathrm{aD}}$ & $5,25^{\mathrm{ac}}$ & $8,70^{\mathrm{aB}}$ & $11,33^{\text {defA }}$ \\
\hline Fenamidona & $25,18^{\text {abcd }}$ & $23,05^{\text {abcde }}$ & $2,13^{\mathrm{ac}}$ & $3,68^{\mathrm{ac}}$ & $5,78^{\mathrm{bcdB}}$ & $11,25^{\text {defA }}$ \\
\hline Fenamidona + propamocarbe & $27,50^{\mathrm{abcd}}$ & $26,10^{\text {abcd }}$ & $2,50^{\mathrm{aD}}$ & $4,53^{\mathrm{ac}}$ & $7,00^{\mathrm{abcB}}$ & $12,70^{\text {abcdeA }}$ \\
\hline Fluopicolide + propamocarbe & $30,68^{a}$ & $28,60^{a}$ & $1,85^{\mathrm{aD}}$ & $5,38^{\mathrm{ac}}$ & $7,45^{\mathrm{abcB}}$ & $15,38^{\mathrm{aA}}$ \\
\hline Propamocarbe & $25,48^{\text {abcd }}$ & $23,56^{\text {abcde }}$ & $1,80^{\mathrm{aD}}$ & $4,15^{\mathrm{ac}}$ & $6,50^{\mathrm{abcB}}$ & $11,08^{\text {defA }}$ \\
\hline Ciazofamida & $27,73^{\text {abcd }}$ & $25,75^{\text {abcde }}$ & $2,05^{\mathrm{aD}}$ & $4,30^{\mathrm{ac}}$ & $7,15^{\mathrm{abcB}}$ & $10,68^{\text {efA }}$ \\
\hline Fluazinam & $22,83^{d}$ & $20,05^{e}$ & $2,00^{\mathrm{aB}}$ & $3,55^{\mathrm{aB}}$ & $6,95^{\mathrm{abcA}}$ & $7,15^{\mathrm{gA}}$ \\
\hline CV (\%) & 10,62 & 12,08 & 17,20 & & & \\
\hline
\end{tabular}

$\mathrm{CV}$ : coeficiente de variação; *médias seguidas de mesma letra minúscula na coluna e maiúsculas na linha não diferem pelo teste de Tukey a $5 \%$ de probabilidade. 
Tabela 3. Severidade e área abaixo da curva de progresso da pinta preta obtida em plantas de batata (cultivar Monalisa) tratadas com fungicidas. Pilar do Sul, São Paulo, outubro a dezembro 2009.

\begin{tabular}{|c|c|c|}
\hline Tratamentos & $\begin{array}{c}\text { Severidade \% } \\
\text { de área foliar } \\
\text { afetada } \\
\text { (87 DAE) }\end{array}$ & AACPPP \\
\hline Picoxistrobina & $5,76^{i j}$ & $1,83^{\text {ghi }}$ \\
\hline Azoxistrobina & $7,75^{\text {hij }}$ & $2,88^{\text {efghi }}$ \\
\hline Azoxistrobina + difenoconazol & $4,25^{j}$ & $1,20^{i}$ \\
\hline Piraclostrobina + metiram & $14,25^{\text {efghi }}$ & $5,18^{\text {defgh }}$ \\
\hline Piraclostrobina + metconazol & $5,75^{i j}$ & $1,45^{\text {hi }}$ \\
\hline Trifloxistrobina + tebuconazol & $6,50^{i j}$ & $1,50^{\text {hi }}$ \\
\hline Tebuconazol & $20,50^{\text {de }}$ & $7,35^{d}$ \\
\hline Difenoconazol & $18,75^{\text {ef }}$ & $6,28^{\text {def }}$ \\
\hline Flutriafol & $15,50^{\text {efgh }}$ & $5,35^{\text {defgh }}$ \\
\hline Metconazol & $20,75^{\text {cde }}$ & $7,15^{d}$ \\
\hline Boscalida & $18,25^{\text {ef }}$ & $6,68^{\text {de }}$ \\
\hline Boscalida + piraclostrobina & $9,25^{\text {ghij }}$ & $2,38^{\text {fghi }}$ \\
\hline Famoxadona + mancozebe & $17,25^{\text {efg }}$ & $5,58^{\text {defg }}$ \\
\hline Iprodiona & $29,00^{\mathrm{bcd}}$ & $12,83^{c}$ \\
\hline Pirimetanil & $16,25^{\text {efgh }}$ & $5,48^{\text {defg }}$ \\
\hline Iprodiona + pirimetanil & $10,25^{\text {fghij }}$ & $3,03^{\text {efghi }}$ \\
\hline Ciprodinil & $12,50^{\text {fghij }}$ & $4,30^{\text {defgh }}$ \\
\hline Fluazinam & $29,50^{\text {bc }}$ & $13,33^{c}$ \\
\hline Clorotalonil & $36,75^{b}$ & $18,08^{b}$ \\
\hline Testemunha & $82,25^{a}$ & $34,98^{a}$ \\
\hline CV (\%) & 20,64 & 17,78 \\
\hline
\end{tabular}

DAE: dias após a emergência; AACPPP: área abaixo da curva de progresso da pinta preta; médias seguidas da mesma letra não diferem entre si pelo teste de Tukey a $5 \%$ de probabilidade; $\mathrm{CV}$ : coeficiente de variação. tratamentos. Os tratamentos à base de clorotalonil, fluazinam e iprodiona foram os menos eficazes. Os valores da AACPPP variaram de 1,20 a 34,98 .

A variação na severidade e a evolução da pinta preta proporcionada pelos fungicidas, em relação à testemunha, influenciaram a produtividade total, comercial e a classificação de tubérculos (Tabela 4). Os maiores níveis de produtividade total foram obtidos com picoxistrobina, azoxistrobina + difenoconazol, trifloxistrobina + tebuconazol, sendo esses superiores a clorotalonil e semelhantes aos demais. As parcelas tratadas com tebuconazol, flutriafol, iprodiona e clorotalonil não diferiram da testemunha para essa característica. Com relação à produtividade comercial de tubérculos, apenas a proporcionada por clorotalonil não diferiu da testemunha. Azoxistrobina + difenoconazol foi superior aos fungicidas tebuconazol, difenoconazol, flutriafol, metconazol, boscalida, famoxadona + mancozebe, iprodiona, pirimetanil, fluazinam e clorotalonil, porém semelhante aos demais. Todos os fungicidas proporcionaram classificação superior de tubérculos em relação à testemunha. Nas parcelas testemunhas não houve diferenças significativas entre as quatro classes de tubérculos. As maiores quantidades de tubérculos classe I foram obtidas com os fungicidas picoxistrobina, piraclostrobina + metconazol e trifloxistrobina + tebuconazol, sendo esses superiores a iprodiona, pirimetanil, clorotalonil, e semelhantes aos demais tratamentos. As maiores produçóes de tubérculos pertencentes à classe II foram promovidas pelos tratamentos azoxistrobina

Tabela 4. Produtividade Total, comercial e classificação de tubérculos comerciais obtidos de plantas de batata (cultivar Monalisa) tratadas com fungicidas. Pilar do Sul, São Paulo, outubro a dezembro 2009.

\begin{tabular}{|c|c|c|c|c|c|c|}
\hline \multirow{2}{*}{ Tratamentos } & \multicolumn{2}{|c|}{ Produtividade $\left(10 \mathrm{~m}^{-2}\right)$} & \multicolumn{4}{|c|}{ Classificação de tubérculos comerciais $\left(10 \mathrm{~m}^{-2}\right)$} \\
\hline & Total & Comercial & Classe IV & Classe III & Classe II & Classe I \\
\hline Picoxistrobina & $29,70^{a}$ & $24,85^{\mathrm{ab}}$ & $3,25^{a c}$ & $5,15^{\mathrm{aBC}}$ & $7,45^{\mathrm{abcdB}}$ & $11,68^{\mathrm{aA}}$ \\
\hline Azoxistrobina & $26,95^{\mathrm{ab}}$ & $25,25^{\mathrm{abc}}$ & $3,03^{a c}$ & $5,65^{\mathrm{aBC}}$ & $7,75^{\mathrm{abcB}}$ & $10,75^{\mathrm{abcA}}$ \\
\hline Azoxistrobina + difenoconazol & $29,95^{a}$ & $29,68^{a}$ & $3,85^{\mathrm{aB}}$ & $6,15^{\mathrm{aB}}$ & $9,18^{\mathrm{aA}}$ & $11,00^{\mathrm{abcA}}$ \\
\hline Piraclostrobina + metiram & $28,80^{\mathrm{ab}}$ & $27,58^{\mathrm{ab}}$ & $3,08^{a c}$ & $6,08^{\mathrm{aB}}$ & $8,88^{\mathrm{abA}}$ & $11,60^{\mathrm{abA}}$ \\
\hline Piraclostrobina + metconazol & $27,70^{\mathrm{ab}}$ & $25,88^{\text {abcde }}$ & $3,18^{a c}$ & $4,33^{\mathrm{aBC}}$ & $7,05^{\mathrm{abcdB}}$ & $11,98^{\mathrm{aA}}$ \\
\hline Trifloxistrobina + tebuconazol & $29,75^{a}$ & $27,90^{\mathrm{ab}}$ & $5,00^{\mathrm{aBC}}$ & $4,13^{\mathrm{ac}}$ & $7,03^{\mathrm{abcdB}}$ & $12,10^{\mathrm{aA}}$ \\
\hline Tebuconazol & $22,75^{\mathrm{abc}}$ & $20,95^{\text {cdef }}$ & $3,08^{\mathrm{aB}}$ & $4,70^{\mathrm{aB}}$ & $5,68^{\mathrm{abcdB}}$ & $8,85^{\mathrm{abcA}}$ \\
\hline Difenoconazol & $23,48^{\mathrm{ab}}$ & $21,10^{\text {bcdef }}$ & $3,20^{\mathrm{aB}}$ & $4,85^{\mathrm{aB}}$ & $5,88^{\mathrm{abcdB}}$ & $8,75^{\mathrm{abcA}}$ \\
\hline Flutriafol & $22,20^{\mathrm{abc}}$ & $20,00^{\text {bcdef }}$ & $3,15^{\mathrm{aB}}$ & $4,72^{\mathrm{aB}}$ & $5,76^{\mathrm{abcdB}}$ & $8,63^{\mathrm{abcA}}$ \\
\hline Metconazol & $23,40^{\mathrm{ab}}$ & $20,05^{\text {cdef }}$ & $3,00^{\mathrm{aB}}$ & $4,75^{\mathrm{aB}}$ & $5,62^{\mathrm{abcdB}}$ & $9,65^{\mathrm{abcA}}$ \\
\hline Boscalida & $28,68^{\mathrm{ab}}$ & $25,55^{\text {abcde }}$ & $3,30^{a c}$ & $4,30^{\mathrm{aBC}}$ & $7,05^{\mathrm{abcdB}}$ & $10,85^{\mathrm{abcA}}$ \\
\hline Boscalida + piraclostrobina & $27,80^{\mathrm{ab}}$ & $26,85^{\mathrm{abcd}}$ & $4,15^{\mathrm{aB}}$ & $5,68^{\mathrm{aB}}$ & $6,45^{\mathrm{abcdB}}$ & $11,38^{\mathrm{abA}}$ \\
\hline Famoxadona + mancozebe & $25,85^{\mathrm{ab}}$ & $24,40^{\text {abcdef }}$ & $3,08^{a c}$ & $5,20^{\mathrm{aBC}}$ & $6,58^{\mathrm{abcdB}}$ & $9,95^{\mathrm{abcA}}$ \\
\hline Iprodiona & $22,25^{a b c}$ & $19,78^{\text {ef }}$ & $2,63^{\mathrm{aB}}$ & $3,85^{\mathrm{aB}}$ & $4,15^{\mathrm{cdB}}$ & $7,90^{\mathrm{bcA}}$ \\
\hline Pirimetanil & $22,98^{\mathrm{ab}}$ & $20,83^{\text {cdef }}$ & $3,03^{\mathrm{aB}}$ & $4,13^{\mathrm{aB}}$ & $5,15^{\mathrm{bcdAB}}$ & $7,48^{\mathrm{cA}}$ \\
\hline Iprodiona + pirimetanil & $24,73^{\mathrm{ab}}$ & $23,40^{\text {abcdef }}$ & $3,02^{\mathrm{ac}}$ & $5,40^{\mathrm{aBC}}$ & $6,50^{\mathrm{abcdB}}$ & $10,25^{\mathrm{abcA}}$ \\
\hline Ciprodinil & $24,58^{\mathrm{ab}}$ & $23,55^{\text {abcdef }}$ & $2,63^{\mathrm{aB}}$ & $4,2 O^{a B}$ & $4,88^{\mathrm{cdB}}$ & $10,30^{\mathrm{abcA}}$ \\
\hline Fluazinam & $23,05^{a b}$ & $20,75^{\text {cdef }}$ & $2,68^{\mathrm{aB}}$ & $3,75^{\mathrm{aB}}$ & $5,50^{\mathrm{abcdB}}$ & $8,90^{\mathrm{abcA}}$ \\
\hline Clorotalonil & $21,50^{\mathrm{bc}}$ & $17,85^{\mathrm{fg}}$ & $2,60^{a B}$ & $2,55^{\mathrm{aB}}$ & $5,33^{\mathrm{bcdA}}$ & $7,32^{\mathrm{cA}}$ \\
\hline Testemunha & $14,58^{c}$ & $11,75^{9}$ & $3,33^{\mathrm{aA}}$ & $3,30^{\mathrm{aA}}$ & $3,70^{\mathrm{dA}}$ & $2,65^{\mathrm{dA}}$ \\
\hline CV (\%) & 20,64 & 15,52 & & & & \\
\hline
\end{tabular}

Médias seguidas de mesma letra minúscula na coluna e maiúsculas na linha não diferem pelo teste de Tukey a 5 \% de probabilidade; CV: coeficiente de variação. 
+ difenoconazol, piraclostrobina + metiram e azoxistrobina, sendo os demais semelhantes à testemunha. Não foram observadas diferenças significativas entre os tratamentos quanto à produçấo de tubérculos das classes III e IV.

Os altos potenciais destrutivos da requeima e da pinta preta reduziram de forma significativa a área foliar, a produção total, comercial e a qualidade de tubérculos nos dois experimentos. $\mathrm{O}$ uso de fungicidas limitou de forma significativa o desenvolvimento das duas doenças nas parcelas tratadas e permitiu que as cultivares Agata e Monalisa pudessem completar o ciclo e expressassem seu potencial produtivo.

De maneira geral, os fungicidas que se destacaram no controle da requeima em folhas também foram efetivos em hastes. O comportamento de produtos em hastes é pouco explorado em nossas condiçóes, porém esse assume relevância quando se considera aspectos como o maior risco de infecção de tubérculos quando as hastes estáo doentes e o fato dessas terem alto potencial de alojar oósporos originados de reproduçáo sexuada (GedDens et al., 2002).

A alta eficácia de fluopicolide + propamocarbe no controle da requeima da batata, observada no experimento 1 , também foi constatada por BARDSLEY et al. (2006), que verificaram a superioridade desse, em relação ao dimetomorfe + mancozebe, fluazinam e ciazofamida. TAFForEaU et al. (2006), analisando 29 experimentos realizados na Europa nas safras 2002 a 2004, observaram que fluopicolide + propamocarbe proporcionou excelente proteçáo da área foliar, sendo superior a dimetomorfe + mancozebe, fluazinam e mancozebe. Schepers et al. (2014), comparando experimentos realizados na Dinamarca, Reino Unido, Holanda e Alemanha nas safras 2006 a 2011, verificaram que fluopicolide + propamocarbe foi um dos tratamentos que mais consistência apresentou na reduçáo do progresso da requeima. Além de alto potencial protetor da parte área, a mistura tem apresentado controle significativo da doença em tubérculos e elevada açáo sobre grupos de compatibilidade A1 e A2 (Braum et al., 2014; Wanninguem et al., 2014). Fluopicolide, pertencente à classe das benzamidas, interfere na divisão celular modificando proteínas espectrinas, relacionadas com a estabilidade e sustentaçáo das membranas celulares de hifas e zoósporos. Estudos biológicos realizados indicam que fluopicolide atua limitando a liberação e a motilidade de zoósporos, a germinação de cistos, o crescimento micelial, além de possuir elevada ação protetora, residual, curativa, antiesporulante e resistência às chuvas (Toquin et al., 2007; Töfoli et al., 2012b; Töfoli et al., 2014b). Destaca-se ainda que o seu mecanismo inédito de ação permite agir sobre raças de P. infestans resistentes a acilalaninas, QoIs e amidas de ácido carboxílico, além de não se conhecer até o presente momento resistência a esse fungicida (Frac, 2015).

Os consideráveis níveis de controle obtidos para fenamidona neste estudo também foram verificados por TöFolı et al. (2003a), ao avaliarem sua eficiência isolado e em mistura com clorotalonil e fosetil-Al no controle da requeima do tomate.
Características positivas, como eficiência sobre os grupos de compatibilidade A1 e A2 de P. infestans, raças resistentes a mefenoxam, bem como açáo sobre a pinta preta, tornam fenamidona uma alternativa estratégica no manejo de doenças foliares da batata (Gudmestad; PASChe, 2007). É importante destacar que fenamidona, pertence à classe das imidazolinonas, atua inibindo a respiraçáo mitocondrial ao nível do Complexo III, citocromo bcl e apresenta ação translaminar. Os elevados níveis de controle de fenamidona + propamocarbe observados neste trabalho concordam com os obtidos por TAFFOREAU et al. (2009). Esses autores, comparando o resultado de quatro campos experimentais, relataram que fenamidona + propamocarbe promoveu elevado e consistente controle da requeima, sendo semelhante ao fluopicolide + propamocarbe, mandipropamida, dimetomorfe + mancozebe e ciazofamida e superior a fluazinam e zoxamida + mancozebe. A superioridade da mistura de fenamidona com propamocarbe em relação à fenamidona e propamocarbe isolados, observada nesse trabalho, pode ser justificada pela somatória de dois mecanismos distintos de ação, diferentes níveis de sistemicidade, maior ação protetora, residual e tenacidade da mistura (Tö̈OLI et al., 2012b; TÖFOLI et al., 2014b).

Específico sobre oomicetos, propamocarbe alcançou os melhores resultados quando utilizado em mistura com fluopicolide e fenamidona. Pertencente à classe dos carbamatos, esse afeta a integridade da membrana celular alterando sua permeabilidade e permitindo o efluxo de constituintes celulares básicos como fosfatos, carboidratos e proteínas. Considerado um fungicida com baixo risco de selecionar raças resistentes de P. infestans, esse produto é altamente recomendado em programas integrados de controle da requeima da batata (FrAC, 2015).

Neste estudo, os fungicidas dimetomorfe (amida do ácido cinâmico), bentiavalicarbe (valinamidas) e mandipropamida (mandelamidas) foram altamente eficazes no controle da requeima da batata, diferindo principalmente em função da mistura testada. Inibidores potentes do crescimento micelial, germinação de esporângios e zoósporos, esses fungicidas atuam sobre a biossíntese de fosfolipídios e na deposição da parede celular (síntese da celulose). Possuem diferentes níveis de ação translaminar e tenacidade, podendo atuar como protetores, curativos, antiesporulantes, além de apresentarem baixo a médio risco de selecionarem raças resistentes de $P$. infestans (GIsI et al., 2007; TöFOLI et al., 2012; TÖFOLI et al., 2014; FRAC, 2015).

Dimetomorfe + ametoctradina seguido de dimetomorfe + clorotalonil proporcionaram os melhores resultados, sendo sempre semelhantes aos melhores tratamentos, enquanto que a mistura com mancozebe apresentou níveis intermediários de controle. Tal fato deve-se provavelmente à maior capacidade de ametoctradina e clorotalonil aderirem à superfície tratada (Gold et al., 2009; SuheRi; Latin, 1991). A superioridade de dimetomorfe + clorotalonil em relação à mistura com mancozebe também foi observada por CANTERI et al. (1993). Em Pilar do Sul, São Paulo, em mistura de dimetomorfe com ametoctradina 
proporcionou elevados níveis de controle da requeima, confirmando os resultados de ReImann et al. (2010a; 2010b), TeGGe et al. (2012), Töfoli et al. (2014a) e PARRAdo et al. (2014). A mistura ametoctradina + metiram, por sua vez, promoveu níveis intermediários de controle, provavelmente devido ao menor potencial de controle de metiram aliado a fatores altamente propícios à requeima, como uso de cultivar suscetível e ocorrência condiçóes climáticas favoráveis. Ametoctradina, pertence à nova classe das pirimidilaminas, caracteriza-se por inibir a respiração no Complexo III, citocromo bc1, no sítio Qo (QoI, inibidor externo da quinona), subsite da ligação da estigmatelina (Gold et al., 2009; KlapPach; Walker, 2010, FrAC, 2015). Caracteriza-se por atuar sobre a formaçáo, liberação e mobilidade de zoósporos e germinação de cistos. O seu modo de ação inédito permite que atue sobre raças resistentes de oomicetos, tornando-o uma alternativa para o manejo da resistência em mistura com outros fungicidas.

A redução significativa do progresso da requeima observada para mandipropamida e mandipropamida + clorotalonil neste trabalho também é destacada por outros autores. Segundo KAPPES; HugGenberger (2007), mandipropamida apresentou resultados superiores e mais consistentes do que dimetomorfe + mancozebe, ciazofamida e cimoxanil + mancozebe. SCHEPERS et al. (2014) também verificaram a elevada redução do progresso da requeima na cultura da batata proporcionado por mandipropamida em experimentos realizados na Europa nas safras 2007 a 2011. Cooke; Little (2010) destacaram que mandipropamida representou uma alternativa segura para o manejo da requeima em áreas nas quais prevalecem isolados A2 resistentes a acilalaninas.

O resultado promissor de bentiavalicarbe, observado no experimento 1, também é destacado por HofMan; VAN OUdHEUSEN (2004). Segundo esses, bentiavalicarbe + mancozebe reduziu consideravelmente a requeima, sendo superior a dimetomorfe + mancozebe, fluazinam e mancozebe. Segundo Schepers et al. (2014), bentiavalicarbe em mistura com mancozebe promoveu controle significativo da requeima nos experimentos realizados na Europa nas safras 2006 a 2010. Mryake et al. (2005) também observaram elevados níveis de controle de bentiavalicarbe no controle da requeima em campos de tomate e batata.

O comportamento intermediário de ciazofamida verificado neste estudo também foi constatado em campos experimentais realizados com esse fungicida na Holanda na safra 2007 e no Reino Unido nas safras 2006 e 2007 (SCHEpers et al. 2014). Cabe destacar que esses resultados diferem dos elevados níveis de controle obtidos por Ebersold (2002), Mitani et al. (2005) e por Schepers et al. (2014) em experimentos realizados na Dinamarca (Safras 2006 e 2007), Holanda (Safras 2006, 2008 e 2009) e Alemanha (Safras 2007, 2008 e 2009). A alta suscetibilidade da cultivar Agata, a alta pressão de requeima observada no decorrer do experimento e o intervalo de aplicaçấo adotado podem ter limitado de alguma forma o potencial de controle de ciazofamida em Pilar do
Sul. Específico sobre oomicetos, esse imidazol age em um sitio metabólico distinto inibindo a respiração no Complexo III, citocromo bc1, sitio Qi (QiI, inibidor interno da quinona), sendo eficaz sobre todos os estágios de vida de $P$. infestans. Apresenta excelente ação protetora, considerável ação residual e resistência à chuva, características altamente desejáveis para um antioomiceto ser incorporado em sistemas de previsão ou programas de aplicaçáo (DesNouck et al., 2012; Töfoli et al., 2012b; TöFoli et al., 2014b; Frac, 2015).

As misturas famoxadona + cimoxanil + mancozebe, famoxadona + cimoxanil e cimoxanil + zoxamida apresentaram níveis intermediários de controle, sendo semelhantes entre si e superiores a famoxadona + mancozebe e fluazinam. Os resultados positivos de famoxadona + cimoxanil e famoxadona + cimoxanil + mancozebe observados neste estudo também foram observados por KirK et al. (2003), WALdenMAier (2004) e MaY et al. (2005). TöFoli et al. (2003b) observaram elevados níveis de controle da requeima do tomateiro para famoxadona + cimoxanil. De maneira geral, famoxadona + mancozebe apresentou níveis inferiores de controle da requeima quando comparado às misturas com cimoxanil. Tal fato pode ser justificado pela sistemicidade limitada de famoxadona em relaçáo ao cimoxanil e à baixa tenacidade de mancozebe. Cabe destacar que famoxadona + mancozebe apresentou níveis intermediários de controle da pinta preta. Pertencente à classe das oxazolidinadionas, famoxadona caracteriza-se por ser um potente inibidor da respiraçấo mitocondrial ao nível do citocromo III, citocromo bc1 no sitio Qo (QoI, inibidor externo da quinona). Alta eficácia biológica, resistência à chuva e considerável ação residual são características marcantes desse fungicida (ANDRIEU et al., 2001; SAUTER, 2007; Töfoli et al., 2014b). O cimoxanil da classe das acetamidas possui considerável ação translaminar, o que lhe confere significativa ação protetora, curativa, antiesporulante e resistência à precipitaçóes. Possui mecanismo de ação desconhecido, açáo limitada sobre a liberaçấo e a germinação de zoósporos e inibe fortemente o crescimento micelial (Hillebrand, Zundel; 2007; Töfoli et al., 2014b; FraC, 2015). Cimoxanil apresenta baixa ação residual devido à sua rápida degradação, o que torna necessário o seu uso em mistura com outros fungicidas como mancozebe, famoxadona e zoxamida. Semelhantemente, a mistura cimoxanil + zoxamida destacou-se em relação à cimoxanil + mancozebe. Tal fato pode ser justificado pela alta capacidade de zoxamida aderir e persistir na superfície foliar (Young, 2007). Zoxamida, pertencente à classe das benzamidas, representa uma alternativa segura para $\mathrm{o}$ manejo da requeima graças ao seu mecanismo de ação distinto sobre a divisão celular (mitose) e características técnicas como elevada açẫo protetora, resistência à chuva, ação sobre $A$. solani e baixo risco de resistência cruzada com mefenoxam, dimetomorfe, cimoxanil e inibidores da respiração (QoI) (BRADSHAw; SChepers, 2001; TöFoli et al., 2012b; TöFoli et al., 2014b).

Nesse estudo, mefenoxam + clorotalonil destacou-se em relaçáo à mefenoxam + mancozebe. Como em outras situaçôes 
observadas nesse trabalho, esse resultado pode ser justificado pela menor tenacidade de mancozebe em relaçáo ao clorotalonil (Suehi; Latin, 1991). A considerável açáo de mefenoxam no controle da requeima observada em Pilar do Sul também foi constatada por MANTECón (2009) em experimentos conduzidos durante 20 anos na Argentina. O fungicida mefenoxam (metalaxil-M), isômero mais ativo do metalaxil, pertence à classe das acilalaninas e representa um marco histórico no controle de oomicetos (MülLer; GisI, 2007). Esse inibe a síntese de RNA ribossômico, resultando no colapso da síntese de proteína na célula fúngica. Caracteriza-se por inibir todas as fases do processo infeccioso após a formação do haustório primário, ou seja, a penetração, a colonização e a esporulação, sem atuar nas demais. A elevada sistemicidade de mefenoxam confere ao fungicida significativa ação protetora, curativa, persistência nos tecidos e resistência às chuvas (Singh; PUNDHIR, 2004; TÖFOLI et al., 2012b; TÖFOLI et al., 2014b).

Piraclostrobina em mistura com metiram apresentou nível intermediário de controle da requeima da batata. Pertencente à classe das estrobilurinas, piraclostrobina caracteriza-se inibir a respiraçấo mitocondrial ao nível do citocromo III, citocromo bc1 no sitio Qo (QoI, inibidor externo da quinona) e por possuir excelente açáo protetora (SAUTER, 2007; FrAC, 2015). Além de eficaz no controle da pinta preta nas culturas da batata e tomate, piraclostrobina é a única estrobilurina com uso autorizado para requeima da batata no Brasil.

Fluazinam, típico fungicida de contato, promoveu níveis inferiores de controle da requeima e pinta preta quando comparados com fungicidas com características sistêmicas. SCHEPERS et al. (2014) observaram consideráveis níveis de controle da requeima em experimentos realizados no Reino Unido nas safras 2007, 2008 e 2009. Nos campos conduzidos na Holanda (safra 2007) e Alemanha (2009), fluazinam apresentou níveis de controle inferiores, como observado nesse estudo. Fluazinam, pertence à classe das dinitroanilina, apresenta excelente ação protetora, bom efeito residual e resistência à chuva (Töғfoli $e t a l$., 2012b; Töfolı et al., 2014b). Atua inibindo a germinação de esporângios e conídios, a formação de apressórios, a penetração, o crescimento de hifas e a esporulaçāo. O fluazinam inibe a respiração desacoplando a fosforilação oxidativa na célula fúngica. Apresenta baixo risco de selecionar patógenos resistentes, possui baixa toxicidade e pode ser considerado estratégico para ser utilizado em programas de aplicaçáo ou em mistura com fungicidas específicos (Whittingham, 2007).

As maiores reduçôes da severidade e progresso da pinta preta foram obtidas com as estrobilurinas (azoxistrobina, piraclostrobina, trifloxistrobina, picoxistrobina) isoladas ou em mistura com triazóis ou boscalida, iprodiona + pirimetanil e ciprodinil. Os triazóis, boscalida e famoxadona + mancozebe e pirimetanil apresentaram comportamento intermediário, enquanto que iprodiona, fluazinam e clorotalonil foram os menos eficientes.

Os elevados níveis de controle da pinta preta obtidos com as estrobilurinas neste estudo também foram observados na literatura para azoxistrobina (LeIminger; HausLANDen, 2009; KuZnetsova et al., 2009; Horsfield et al., 2010); piraclostrobina (Jilderda et al., 2006; MacDonald et al., 2007; Leiminger; Hauslanden, 2009) e trifloxistrobina (Leiminger; Hauslanden, 2009). Tal fato pode ser explicado pela alta fungitoxicidade e consideráveis níveis de ação protetora, curativa, antiesporulante e resistência à chuva apresentados por esses fungicidas (BARTLETt et al., 2001; Töfoli et al., 2005; TöFOLI et al., 2012b; TöғOLI et al., 2014b).

Os triazóis difenoconazol, metconazol, tebuconazol e flutriafol também apresentaram consideráveis níveis de controle da pinta preta da batata, porém quase sempre inferiores às estrobilurinas e às suas misturas com essas. São fungicidas considerados altamente eficazes sobre a pinta preta, sendo considerados padrôes de controle a partir da década de 1990. Inibidores da síntese de ergosterol, esses fungicidas são caracterizados por serem sistêmicos, apresentarem elevado potencial protetor, ação curativa, período residual significativo e resistência às chuvas (Töfoli et al., 2005; KuCK; Vors, 2007; Töfoli et al., 2012b; Töғolı et al., 2014b). A superioridade de tebuconazol, em relação a produtos de contato como fluazinam e clorotalonil, no controle da pinta preta também foi observada por Shtienberg et al. (1996). Semelhantemente ao que foi observado neste trabalho, MANTECón (2000) verificou bons níveis de controle de $A$. solani com metconazol, sendo esse superior a iprodiona e semelhante a tebuconazol. Töfoli et al. (2003) obtiveram bons níveis de controle da pinta preta do tomateiro com tebuconazol e difenoconazol.

A similaridade de controle entre as estrobilurinas isoladas e suas misturas com triazóis e boscalida, e a superioridade dessas em relação a triazóis e boscalida isolados demonstram a alta capacidade que as estrobilurinas apresentam para controlar A solani. Tal fato pode ser explicado pela alta fungitoxicidade e diferentes níveis de atividade sistêmica que essas apresentam (BARTLETt et al., 2001). Destaca-se, ainda, que o aumento da ação residual e resistência à chuva observada para essas misturas em outros estudos não influenciaram diretamente o controle da pinta preta no campo (Töғoli et al., 2012b; Töғoli et al. 2014b). Provavelmente a alta concentração de inóculo e as condiçóes altamente favoráveis à doença utilizadas em condiçóes controladas podem ter contribuído para uma melhor expressão e destaque das misturas em relação ao uso isolado. As estrobilurinas azoxistrobina, trifloxistrobina, piraclostrobina e picoxistrobina sáo fungicidas que apresentam excelente ação preventiva, curativa e antiesporulante. Desenvolvidas a partir de compostos naturais, apresentam diferentes níveis de sistemicidade, perfil agroecotoxicológico favorável e eficácia comprovada sobre o gênero Alternaria (BARTLETT et al., 2001).

Pertencente à classe das carboxamidas, o fungicida boscalida também inibe a respiração mitocondrial, porém atua no complexo II, através da inibição da enzima succinato desidrogenase. Apresenta açáo protetora, sistêmica, antiesporulante e resistência à chuva (TöFoli et al., 2012b; TöFoli et al., 
2014b). Em Alternaria solani inibe a germinação de conídios, a elongaçáo do tubo germinativo, a formaçáo de apressório, o crescimento micelial e a esporulação (RHeinheimer, 2007). Neste estudo, boscalida foi mais eficaz quando utilizada em mistura com piraclostrobina. De modo geral, os bons níveis de controle de boscalida observados em Pilar do Sul, São Paulo, também foram observados por Horsfield et al. (2010).

As anilinopirimidinas pirimetanil e ciprodinil promoveram níveis consideráveis de controle da pinta preta da batata. Tal fato também foi observado por Töroli et al. (2003), ao avaliarem o potencial desses fungicidas no controle da pinta preta do tomateiro em condiçóes de campo. A inibição da biossíntese de metionina e as características positivas como elevada ação protetora, curativa e resistência a precipitaçóes tornam esses produtos alternativas seguras para serem utilizados isolados ou em misturas no controle e em programas de manejo da resistência (Gisi; Muller, 2007; TöFoli et al., 2012b; Töfoli et al. 2014b; Frac, 2015).

Famoxadona + mancozebe apresentou níveis intermediários da pinta preta em condições de campo. TöFoli et al. (2003) observaram elevados níveis de controle da pinta preta do tomateiro para essa mistura. Como foi dito anteriormente, famoxadona é um potente inibidor da respiração mitocondrial possui considerável ação residual e resistência à ação de precipitaçóes (Andrieu et al., 2000; SAuter, 2007; Töfoli et al., 2014b).

O fungicida iprodiona apresenta reconhecida eficácia no controle de $A$. solani nas culturas de batata e tomate (Töroli et al., 2003). São fungicidas com ação de profundidade e apresentam reconhecida ação curativa e antiesporulante (Töғolı et al. 2012b). Apesar de eficaz no controle da pinta preta, iprodiona apresentou comportamento inferior a estrobilurinas, triazóis, anilinopirimidinas e suas misturas. $\mathrm{O}$ melhor resultado para dessa dicarboximida foi obtido quando essa foi utilizada em mistura com pirimetanil.

O menor nível de controle da pinta preta por clorotalonil em relação aos fungicidas específicos observados neste trabalho podem ser explicados por sua açáo típica de contato. Pertencente à classe das cloronitrilas, esse age em vários sítios do metabolismo celular e destaca-se por sua maior aderência à superfície foliar, considerável capacidade de se redistribuir na planta e baixo risco de selecionar raças resistentes (Töfoli et al. 2013; Töfoli et al., 2014b; FraC, 2015).

O elevado potencial destrutivo da requeima reduziu de forma significativa a produtividade total, comercial e a qualidade de tubérculos nas testemunhas. A redução da severidade e do progresso da doença proporcionada pelos fungicidas permitiu que as parcelas tratadas apresentassem maior produtividade total, comercial e melhor classificação de tubérculos. Os resultados obtidos permitem concluir mais uma vez que o uso de fungicidas no controle da requeima pode contribuir de forma direta sobre o valor comercial da produção. Os reflexos positivos do uso de fungicidas no controle da requeima sobre o rendimento observado neste trabalho também foram constatados para fluopicolide (BARDsLeY et al., 2006; TAFForeau et al., 2006); mandipropamida (KAPpes; Huggenberger, 2007); dimetomorfe (Heremans; Haesaert, 2003; Stein; Kirk, 2003); bentiavalicarbe (Hofman; VAN Oudheusden, 2004); mefenoxam (MANTEcón, 2009); ametoctradina (TegGe et al., 2012; TöFOLI et al., 2014a); propamocarbe, zoxamida e famoxadona (Heremans; Haesaert, 2003). De maneira geral, observou-se que os maiores níveis de controle geraram as melhores produçóes comerciais. Todavia, alguns fungicidas como piraclostrobina + metiram, fenamidona, ciazofamida, famoxadona + cimoxanil e propamocarbe apresentaram níveis intermediários de controle, no entanto, não diferiram dos melhores tratamentos quanto à produçáo comercial de tubérculos. Provavelmente o nível de controle desses fungicidas foi suficiente para que o potencial produtivo da cultivar Agata fosse expresso. Cabe destacar que as parcelas tratadas com piraclostrobina + metiram, no experimento 1, apresentaram produção de tubérculos da classe I semelhante aos melhores tratamentos. Estudos têm provado que algumas estrobilurinas, além de atuarem diretamente sobre o patógeno, apresentam efeitos secundários altamente benéficos à planta, tais como redução da produção de etileno, aumento da atividade da enzima nitrato-redutase, atraso na senescência, aumento dos teores de clorofila e proteínas e reflexos positivos na produçáo (KöEHLe et al., 2002; Venancio et al., 2003).

Semelhantemente à redução da pinta preta proporcionada pelos tratamentos testados, também refletiu sobre a produtividade e a classificação de tubérculos. Os aumentos de produção obtidos neste estudo também foram constatados para os fungicidas azoxistrobina (Bouwman; RujKers, 2004; MACDONALD et al., 2007); trifloxistrobina (Leiminger; Hauslanden, 2009), piraclostrobina (MACDONALD et al., 2007; LEIMINGER; HausLANDEn, 2009), boscalida (Horsfield et al., 2010) e tebuconazol (SHTIENBERg et al., 1996).

A especificidade das acilalaninas, estrobilurinas e carboximidas torna esses fungicidas vulneráveis à seleção de linhagens resistentes de $P$. infestans e $A$. solani (Davidse et al., 1983; PAsche et al., 2004; PAsche; Gudmestad, 2007; FAIRChild et al., 2013). Nesse contexto, o desenvolvimento de misturas conjugando esses fungicidas com produtos inespecíficos de ação tem permitido somar diferentes mecanismos de ação, prolongar a vida útil desses fungicidas e reduzir o risco de ocorrência de resistência (KUCK; GISI, 2007; LUCE, 2014).

Os resultados obtidos nesse estudo evidenciam a existência de um número considerável de fungicidas eficientes para o controle da requeima e pinta preta da batata. $\mathrm{O}$ uso desses produtos deve ser realizado sempre dentro de programas de manejo integrado, sendo observadas todas as recomendaçôes do fabricante quanto à dose, momento da aplicação, número e intervalo de pulverizaçóes, volume, entre outras. Tais critérios são fundamentais para a obtenção de níveis adequados de controle, maior vida útil dos produtos e risco menor de ocorrência de resistência. 

REFERÊNCIAS

ANDRIEU, N.; JAWORSKA, G.; GENET J.L.; BOMPEIX G. Biological mode of action of Famoxadone on Plasmopara viticola and Phytophthora infestans. Crop Protection, Guildford, v.20, n.3, p.253-260, 2001.

BARDSLEY, E.; WEGENER, M.; TAFFOREAU, S. Field development of infinito for late blight control in potatoes. Pflanzenschutz Nachriten Bayer, Leverkussen, v.59, n.2/3, p.281-292, 2006.

BARTLETT, D.W.; CLOUGH, J.M.; GODFREY, C.R.A.; GODWIN, J.R.; HALL, A.A.; HEANEY, S.P.; MAUND, S.J. Understanding the strobilurin fungicides. Pesticide Outlook, Cambrigde, v.12, p. 143-148, 2001.

BOUWMAN, J.J.; RIJKERS, G. The control of Alternaria solani (early blight) with azoxystrobin in potatoes. PPO Special Report, Wageningen, v.10, p.179-188, 2004.

BRADSHAW, N.J., SCHEPERS, H.T.A.M. Experiences with $\mathrm{RH}-117281$ (zoxamide): a new fungicide for the control of potato blight. PPV-Special Report, Munich, n.7, p.173-183, 2001.

BRAUN, C.A.; WANNINGEN, R.; SCHIRRING A. Infinito ${ }^{\circledR}$ : protection against different Phytophthora infestans isolates of the A2 \& A1 mating type. PPO Special Report, n. 16, p.117-122, 2014.

CAMPBELL, C.L.; MADDEN, L.V. Introduction to plant disease epidemiology. New York: Wiley, 1990.

CANTERI, M.G.; FURIATTI, R.S.; PERINO, M.A. Efeito de fungicidas aplicados isoladamente ou em mistura no controle da requeima (Phytophthora infestans) da batata. Summa Phytopathologica, Jaboticabal, v.19, n.2, p.195-198, 1993.

COOKE, L.R.; LITTLE, G. Evaluation of mandipropamid for the control of potato late blight in Northern Ireland. PPO-Special Report, Arras, n.14, p.109-116, 2010.

CRUICKSHANK, G.; STEWART, H.E.; WASTIE, R.L. An illustrated assessment key for foliage blight of potatoes. Potato Research, Wageningen, v.25, n.2, p.213-214, 1982.

DAVIDSE, L.C.; DANIAL, D.L.; VAN WESTEN, C.J. Resistance to metalaxyl in Phytophthora infestans in the Netherlands. The Netherlands Journal of Plant Pathology, v.89, p.1-20, 1983.

DESNOUCK J.; TESTERS J.; VERSMISSEN C. Ranman Top, again a step forwards in late blight control. PPO-Special Report, Arras, n. 15, p. $115-118,2012$.

DIAS, J.A.C.; IAMAUTI, M.T. Doenças da batateira (Solanum tuberosum). In: KIMATI, H.; AMORIN, L.; BERGAMIN FILHO, A.; CAMARGO, L.E.A.; REZENDE, J.A.M (Eds.). Manual de fipatologia: doenças das plantas cultivadas. 4 ed. São Paulo: Ceres, 2005. Vol. 2, p.119-142.

EBERSOLD, D. Ranman, the new marathon fungicide. PPO-Special Report, Edinburgh, v.8, p.225-230, 2002.
FAIRCHILD, K.L.; MILES, T.D.; WHARTON P.S. Assessing fungicide resistance in populations of Alternaria in Idaho potato fields. Crop Protection, v. 49, p.31-39, 2013.

FRAC. Fungicide resistance action commitee. FRAC Code List 2015: fungicides sorted by mode of action. Disponível em: <http://www. frac.info/docs/default-source/publications/frac-code-list/fraccode-list-2015-finalC2AD7AA36764.pdf?sfvrsn=4>. Acesso em: 20 out. 2015.

GEDDENS, R.; SHEPHERD, C.; GENET, J. Stems lesions of potato late blight: biological features and fungicidal control of early-season infections. PPO-Special Report, Edinburgh, v.8, p. 145-154, 2002.

GISI, U.; MÜLLER, U. Anilinopyrimidines: methionine biosynthesis inhibitors. In: Krämer, W.; Schirmer, U. (Ed.). Modern crop protection compounds. Berlin: Verlag, 2007. Vol. 2, p.551-560.

GISI, U.; LAMBERTH, C., MEHL, A.; SEITZ, T. Carboxylic Acid Amide (CAA) fungicides. In: Krämer, W.; Schirmer, U. (Ed.). Modern crop protection compounds. Berlin: Verlag, 2007. Vol. 2, p.651-674.

GOLD, R.; SCHERER, M.; RETHER J.; SPEAKMAN J.; NAVÉ, B.; LEVY T.; STORER R.; MARRIS, D. Initium ${ }^{\circledR}$ : an innovative fungicide of a new chemical class for the control of oomycetes. In: BCPC CONGRESS, 2009, Glasgow. Proceedings... Glasgow: BCPC, 2009. p.1-6.

GUDMESTAD, N.C.; PASCHE J.S. Role of fenamidone in the management of potato early blight. PPO-Special Report, Bologna, v.12, p.175-182, 2007.

HEREMANS, B.; HAESAERT, G. Effects of selected commercial fungicides on late blight infection during the potato growing season 2003. Parasitica, Bruxelles, v.59, n.3/4, p.97-105, 2003.

HILLEBRAND, S.; ZUNDEL, J.L. Newer fungicides with unknown mode of action. In: Krämer, W.; Schirmer, U. (Ed.). Modern crop protection compounds. Berlin: Verlag, 2007. Vol. 2, p.709-726.

HOFMAN, T.W.; VAN OUDHEUSEN, Z. New fungicide benthiavalicarbisopropil + mancozebe for foliar use in potatoes in Europe. PPO-Special Report, Jersey, n. 10, p.125-130, 2004.

HORSFIELD, A.; WICKS, T.; DAVIES, K.; WILSON, D.; PATON S. Effect of fungicide use strategies on the control of early blight (Alternaria solani) and potato yield. Australasian Plant Pathology, Clayton, v.39, n.1, p. 368-375, 2010.

HUGGENBERGER, F.; KNAUF-BEITER, G. Mandipropamid a new fungicides for the control of late blight in potatoes. $P P O-S p e c i a l$ Report, Bologna, v.12, p. 67-76, 2007.

JILDERDA, K.; KRUTS M.; SCHOLTENS R.; JACOBS K.; SINNEMA T. Signum, a novel fungicide for the control of Alternaria spp in potatoes. PPO-Special Report, Tallin, v. 11 , p. $69-75,2006$. 
KAPPES, E.M.; HUGGENBERGER, F. Revus-Field performance and product recommendations against late blight in potatoes in Europe. PPO-Special Report, Bologna, v.12, p.121-128, 2007.

KIRK, W.W.; SCHAFER, R.I.; BERRY D. Evaluation of Tanos, Famoxate and Curzate programs for potato late blight and Alternaria spp. Control, 2002. Fungicide and Nematicide Tests, APS net, St. Paul, v.58, p.104, 2003.

KLAPPACH, K.; WALKER, K. Ametoctradin: a new Oomycete specific fungicide. Phytopathology, St. Paul, v.100, p.63, 2010.

KÖEHLE, H.; GROSSMANN, K.; JABS, T.; GERHARD, M.; KAISER, W.; GLAAB, J.; CONRATH, U.; SEEHAUS, K.; HERMS, S. Physiological effects of the strobilurin fungicide $F 500$ on plants. In: DEHNE, H.W.; GISI, U.; KUCK, K.H.; RUSSELL, P.E.; LYR, H. (Ed.) Modern fungicides and antifungal compounds III. Bonn: Agro Concept Gmbh, 2002. S61-74.

KUCK, K.H.; VORS, J.P. Sterol biosynthesis inhibitors. In: Krämer, W.; Schirmer, U. (Ed.) Modern crop protection compounds. Berlin: Verlag, 2007. Vol. 2, p.605-650.

KUCK, K.H.; GISI, U. FRAC: mode of action classification and resistance risk. In: Krämer, W.; Schirmer, U. (Ed.). Modern crop protection compounds. Berlin: Verlag, 2007. Vol. 2, p.415-432.

KUZNETSOVA, M.A.; SPIGLAZOVA, S.Y.; SMETANINA, T.I.; KOZLOVSKY, B.E.; DERENKO, T.A.; FILIPPOV, A.V. Effect of Quadris applied as an in-furrow spray against the late blight and early blight on a potato foliage. PPO-Special Report, Hamar, v.13, p.275-280, 2009.

LEIMINGER, J.; HAUSLADEN, H. Efficacy of different fungicides for the control of early blight. PPO-Special Report, Hamar, v.13, p. 123-126, 2009.

LUCE, L.T.F. Fungicide resistance: risk and consequence in modern agriculture. Institute for Agriculture and Trade Policy, 2014. Disponível em: <http://www.iatp.org/files/2014_12_23_ Fungicide_LL.pdf $>$. Acesso em: 09 out. 2015.

MACDONALD, W.; PETERS, R.D.; COFFIN, R.H.; LACROIX, C. Effect of strobilurin fungicides on control of early blight (Alternaria solani) and yield of potatoes grown under two $\mathrm{N}$ fertility regimes. Phytoprotection, Quebec, v.88, n.1, p.9-15, 2007.

MANTECÓN, J.D. Management of potato early blight with systemic and non systemic fungicides, 1999. Fungicide and Nematicide Tests, APS net, St. Paul, v.55, p.212-213, 2000.

MANTECÓN, J.D. Importance of potato late blight in Argentina, and the effect of fungicide treatments on yield increments over twenty years. Ciencia e Investigación Agraria, Santiago, v.36, n. 1, p. $115-122,2009$.

MAY, S.R.; CRIST, B.J.; PECK, M.W. Fungicidal control of late blight on potato, 2004. Fungicide and Nematicide Tests, APS net, St Paul, v.60, p.84, 2005.
MITANI, S.; KAMACHI, K.; SUGIMOTO, K. Control of potato late blight by ciazofamid. Journal of Pesticide Science, Tokyo, v.30, n.2, p. $116-119,2005$.

MIYAKE, Y.; SAKAI, J.; SHIBATA, M.; YONEKURA, N.; MIURA, I.; KUMAKURA, K.; NAGAYAMA, K. Fungicidal activity of Benthiavalicarb-isopropyl against Phytophthora infestans and its controlling activity against late blight diseases. Journal Pesticide Science, Tokyo, v.30, n.4, p.390-396, 2005.

MIZUBUTI, E.S.G. Requeima ou mela da batata e tomate. In: Luz, E.D.M.N.; Santos, A.F; Matsuoka, K.; Bezerra, J.L. Doenças causadas por Phytophthora no Brasil. Campinas: Livraria Rural, 2001. p.100-173.

MÜLLER, U.; GISI, U. Newest aspects of nucleic acid synthesis inhibitors: Metalaxyl-M. In: Krämer, W.; Schirmer, U.; JESCHKE, P.; WITSCHEL, M. (Eds.) Modern crop protection compounds. Berlin: Verlag, 2007. Vol. 2, p.739-746.

PARRADO J.A.; PEREIRO, G.A.; RODRÍGUEZ, J.A.D. Efectividad del formulado ametoctradin $30 \%$ + dimetomorf $22,5 \%$ para el control del tizón tardío (Phytophthora infestans) en el cultivo de la papa (Solanum tuberosum). Fitosanidad, v.18, n.1, p.41-43, 2014.

PASCHE, J.S.; GUDMESTAD, N.C. Prevalence and significance of the F129L mutation in Alternaria solani from the United States. PPO-Special Report, Bologna, v.12, p.265-268, 2007.

PASCHE, J.S.; WHARAM, C.M.; GUDMESTAD, N.C. Shift in sensitivity of Alternaria solani in response to Qol fungicides. Plant Disease, St. Paul, v.88, n.2, p.181-187, 2004.

REIFSCHNEIDER, F.J.B.; FURUMOTO, O.; FILGUEIRA, F.A.R. Illustrated key for the evaluation of early blight of potatoes. FAO Plant Protection, Rome, v.32, n.3, p.91-93, 1984.

REIMANN, S.; JILDERDA, K.; GERBER, M.; TEGGE, V.; KLAPPACH, $\mathrm{K}$. Initium ${ }^{\circledR}$ : a new fungicidal active ingredient for the control of Oomycetes. PPO-Special Report, Arras, n. 14, p.89-94, 2010 a.

REIMANN, S.; JILDERDA, K.; GERBER, M.; TEGGE, V.; KLAPPACH, K. Initium ${ }^{\circledR}$ based products for the control of Phytophthora infestans in potatoes. PPO-Special Report, Arras, n. 14, p.95-100, 2010 b.

RHEINHEIMER, J. Succinate dehydrogenase inhibitors. In: Krämer, W.; Schirmer, U. (Ed.). Modern crop protection compounds. Berlin: Verlag, 2007. v. 2, p.496-504.

SAUTER, H. Strobilurins and other complex III Inhibitors. In: Krämer, W.; Schirmer, U. (Ed.). Modern crop protection compounds. Berlin: Verlag, 2007. Vol. 2, p.457-495.

SCHEPERS, H.T.A.M.; BAIN R.; HAUSLADEN, H.; NIELSEN. B.J.; SPITS H.G.; VAN DEN BERG, W.; EVENHUIS, A. Fungicide evaluation to rate efficacy to control leaf late blight for the Euroblight table: results 2006-2013. Applied Plant Research, Wageningen, PPO no. 32502773000, 2014. 42p.

SINGH, R.P.; PUNDHIR, V.S. Uptake, translocation and persistence of metalaxyl in potato. Journal of Mycology and Plant Pathology, Udaipur, v.34, n.1, p.93-95, 2004. 
SHTIENBERG, D.; BLACHINSKY, D.; BEN-HADOR, G.; DINOOR, A. Effects of growing season and fungicide type on the development of Alternaria solani and on potato yield. Plant Disease, St. Paul, v.80, n.9, p.994-998, 1996.

STEVENSON, W.; KIRK, W.; ATALLAH, Z.K. Managing foliar disease: early blight, late blight and white mold. In: Johnson, D.a. (Ed.) Potato health management. St. Paul: APS, 2008. p. 209-222.

STEIN, J.M.; KIRK, W.W. Field optimization of dimetomorph for the control of potato late blight Phytophthora infestans: application rate, interval, and mixtures. Crop Protection, Guildford, v. 22 , p.609-614, 2003.

SUHERI, H.; LATIN, R.X. Retention of fungicides for control of alternaria leaf spot of muskmelon under greenhouse conditions. Plant Disease, St. Paul, v.75, p.1013-1015, 1991.

TAFFOREAU, S.; LATORSE, M.P.; JUHL, O.; BARDSLEY, E. Consento: new experiences on the control of late blight 2007-2008. A summary of recent data with Consento in Europe. PPO-Special Report, Hamar, v.13, p.135-142, 2009.

TAFFOREAU, S.; BARDSLEY, E.; LATORSE, M.P.; FABRÈGES, C.; SCHIRRINGS, A.; WEGMANN, T. Infinito: profile of a novel potato late blight fungicides. Summary of three years of development trials in Europe. PPO-Special Report, Tallinn, v. 11 , p.77-88, 2006.

TEGGE, V.; ERVEN, T.; KIERS, E.; KRUTS, M.; MURRAY, A.; BRIX, H.D. Recommendations and field performance of Initium ${ }^{\circledR}$ based products against Phytophthora infestans in potato. PPO-Special Report, St. Petersburg, v.15, p.119-122, 2012.

TÖFOLI, J.G.; DOMINGUES, R.J.; FERRARI, J.T. Alternaria spp. em oleráceas: sintomas, etiologia, manejo e fungicidas. Biológico, São Paulo, v.77, n.1, p.21-34, 2015.

TÖFOLI, J.G.; DOMINGUES, R.J.; JACOBELIS JR W.; PACHECO M. Ação de amectotradina+dimetomorfe no controle da requeima na cultura da batata. Summa Phytopathologica, Botucatu, v. 40(Suppl.), 2014a.

TÖFOLI, J.G.; DOMINGUES, R.J.; MELO, P.C.T.; FERRARI, J.T. Effect of simulated rain on the efficiency of fungicides in potato late blight and early blight control. Semina: Ciências Agrárias, Londrina, v.35, n.6, p.2977-2990, 2014b.

TÖFOLI, J.G.; MELO, P.C.T.; DOMINGUES, R.J.; FERRARI, J.T. Requeima e pinta preta na cultura da batata: importância, características e manejo sustentável. Biológico, São Paulo, v.75, n. 1, p.33-40, $2013 a$.

TÖFOLI, J.G.; MELO, P.C.T.; DOMINGUES, R.J.; FERRARI, J.T. Controle da requeima e pinta preta da batata por fungicidas: conceitos, evolução e uso integrado. Biológico, São Paulo, v.75, n. 1, p.41-52, $2013 \mathrm{~b}$.

TÖFOLI J.G.; DOMINGUES, R.J.; FERRARI, J.T.; NOGUEIRA, E.M.C. Doenças fúngicas da cultura da batata: sintomas, etiologia e manejo. Biológico, São Paulo, v.74, n.1, p.63-73, 2012a.

TÖFOLI J.G.; MELO, P.C.T.; DOMINGUES, R.J. Ação protetora, residual, curativa e antiesporulante de fungicidas no controle da requeima e da pinta preta da batata em condições controladas. Arquivos do Instituto Biológico, São Paulo, v.79, n.2, p.209-211, 2012 b.

TÖFOLI, J.G.; KUROZAWA, C.; DOMINGUES, R.J. Ação de fungicidas em diferentes fases do ciclo da pinta preta do tomateiro em condições controladas. Summa Phytopathologica, v.3 1, n.2, p.125-132, 2005.

TÖFOLI, J.G.; DOMINGUES R.J.; GARCIA JUNIOR, O. Controle da requeima do tomateiro com fungicidas e seus reflexos na produção. Arquivos do Instituto Biológico, São Paulo, v.70, n.4, p.473-482, 2003.

TÖFOLI, J.G.; DOMINGUES, R.J.; GARCIA JR., O.; KUROZAWA, C. Controle da pinta preta do tomateiro por fungicidas e seus impactos na produção. Summa Phytopatologica, Botucatu, v.29, n.3, p.225-233, 2003.

TOQUIN, V.; BARJA, F.; SIRVEN, C.; BEFFA, R. Fluopicolide a new anti-oomycetes fungicides with a new mode of action induzing perturbation of a spectrin like protein. In: Krämer, W.; Schirmer, U. (Eds.). Modern crop protection compounds. Berlin: Verlag, 2007. Vol. 2, p.675-682.

VENANCIO, W.S.; RODRIGUES, M.A.T.; BEGLIOMINI, E.; SOUZA N.L. Efeitos fisiológicos de fungicidas do grupo das estrobilurinas sobre plantas. UEPG Ciências Exatas e da Terra, Ciências Agrárias e Engenharias, Ponta Grossa, v.9, n.3, p.59-68, 2003.

WALDENMAIER, C.M. Evaluation of fungicides for management of late blight in white potato. Fungicide and Nematicide Tests, APS net. St Paul, v.59, p.83, 2004.

WALE, S.; PLATT, H.W.; CATTLIN, N. Disease pests and disorders of potatoes. Amsterdam: Elsevier, 2008. 179p.

WANNINGEN, R.; BRAUN, C. A.; TAFFOREAU, S. Infinito and protection against tuber blight: modes of action. PPO-Special Report, n.16, p.123-136, 2014.

WHITTINGHAM, W.G. Uncouplers of oxidative phosforylation. In: Krämer, W.; Schirmer, U. (Eds.).Modern crop protection compounds. Berlin: Verlag, 2007. Vol. 2, p.505-527.

YOUNG, D.H. Zoxamide, an antitubulin fungicide for control of oomycete pathogens. In: Krämer, W.; Schirmer, U. (Eds.). Modern crop protection compounds. Berlin: Verlag, 2007. Vol. 2, p.581-590. 